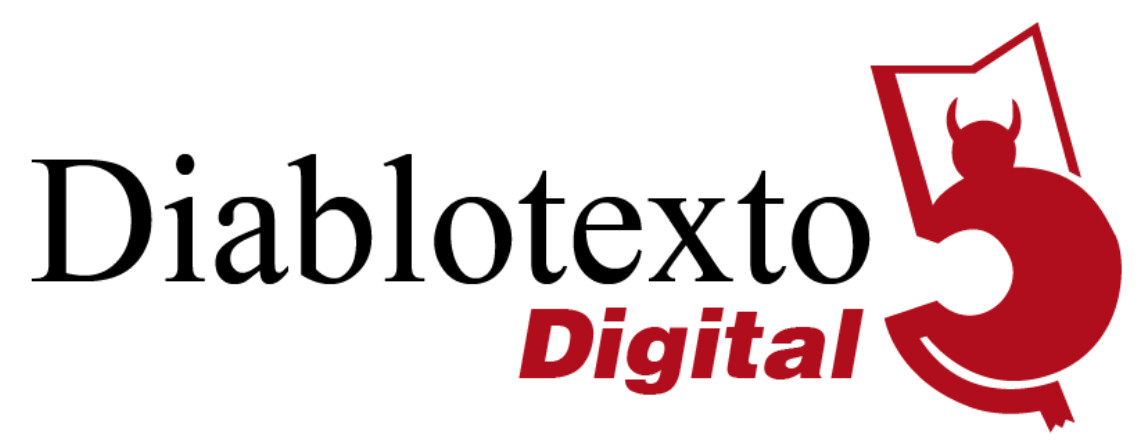

\title{
La intangibilidad de la lírica: la holopoesía de Eduardo Kac
}

The Immaterial Nature of the Lyric: Eduardo Kac's Holopoetry

\author{
Celia Corral Cañas \\ UNIVERSIDAD DE SALAMANCA
}

\begin{abstract}
Resumen: La holopoesía explora los límites del espacio y de la recepción y se constituye como una lírica tridimensional inmaterial. El trabajo de Eduardo Kac resulta pionero y esencial en el género, tanto por sus textos teóricos como, sobre todo, por sus creaciones artísticas. La lectura de los poemas holográficos solo puede ser percibida en relación con el ángulo del lector, con su acercamiento a la obra y con su propio dinamismo. De este modo, el texto, en constante mutación, se convierte en un evento espacio-temporal y genera una experiencia estética significativamente nueva y distinta en cada receptor, en cada recepción.
\end{abstract}

Palabras clave: holopoesía, Eduardo Kac, lírica, poesía digital

Abstract: Holopoetry explores the boundaries of space and reception and stands as a tridimensional, non-material lyric. Eduardo Kac's work pioneers the genre, not only by his theoretical texts, but more importantly for his artistic creations. The lecture of holographic poems can only be conceived in terms of the lecturer's point of view, with their approach to the work and its own motion. Thus, the constantly changing text becomes an event developed in both the spatial and temporal categories and generates a remarkably new aesthetic experience, mutable and different from one spectator to another.

Key words: Holopoetry, Eduardo Kac, Lyric, Digital Poetry 


\section{Las múltiples dimensiones de la poesía}

El género poético, por su propia naturaleza dúctil, simbólica y volátil, experimenta una diversidad de formas que comprenden a su vez una diversidad de canales, medios y dimensiones. La holopoesía encarna, precisamente desde la aparente ausencia de fisicidad, posibilidades inmateriales e intangibles de la lírica.

La confluencia de la literatura contemporánea con los instrumentos tecnológicos de nuestra era facilita la emergencia de nuevas fórmulas verbales creativas en continuo diálogo con el medio y con la percepción. El cuestionamiento de la rigidez de la página convencional y la exploración de nuevos caminos para transmitir mensajes artísticos a un receptor participativo encuentra sus raíces en la propia tradición literaria y florece con especial propulsión en las vanguardias históricas, en la Neovanguardia y, sobre todo, en las "vanguardias digitales"1. La generalización del uso de internet en el área editorial ha impulsado, además de la digitalización de obras literarias y del empleo de la red como canal comunicativo y medio de publicación (con una gran vitalidad, desde los blogs hasta las redes sociales), el nacimiento de nuevos géneros digitales nativos al medio, como la poesía hipertextual, la videopoesía, la poesía multimedia, la poesía transmedia, la poesía computacional, la poesía creada para dispositivos móviles o las creaciones híbridas y transfronterizas.

Sin embargo, el surgimiento de la holopoesía a principios de los años ochenta resulta llamativo por su carácter pionero, así como por la originalidad de su propuesta conceptual en analogía con metáforas representativas de nuestro tiempo asociadas con la materia, como la "liquidez" (Zygmund Bauman) o el "simulacro" (Jean Baudrillard); con el espacio, como la "heterotopía" (Michael Foucault), el "no-lugar" (Marc Augé) o lo "rizomático" (Gilles Deleuze y Félix Guattari); con el tiempo, como el "presentismo" y lo "efímero" (Michel Maffesoli, Gilles Lipovetsky); con la actitud del receptor, como lo "lúdico" (Johan Huizinga); o con la relevancia del significante como

\footnotetext{
${ }^{1}$ Las "vanguardias digitales" cristalizan en muchas ocasiones los principios de los movimientos vanguardistas previos a la esfera virtual, como asevera José Luis Molinuevo: "los ideales de las vanguardias históricas se cumplen en las vanguardias digitales” (2006: 20).
} 
significado, del medio como mensaje (Marshall McLuhan). La poesía hologramática, por tanto, representa algunas de las definiciones de nuestro constructo cultural desde una perspectiva artística, innovadora y autoconsciente.

\section{La voz lírica del holograma}

La holopoesía, poesía holográfica o poesía hologramática consiste en una lírica creada mediante la técnica holográfica y relacionada con el concepto de VRML (Virtual Reality Modelling Literature) y de Aesthetic Animism (Johnston, 2011: 64, 69), es decir, en la ilusión óptica de poemas virtuales tridimensionales e inmateriales.

El término "holopoesía" fue acuñado por el artista experimental brasileño y reconocido holopoeta Eduardo Kac, quien presentó el primer holopoema en 1983 y la primera serie de holopoemas en 1985, titulada Holopoetry. Kac explica este género con la siguiente descripción:

\footnotetext{
Un poema holográfico $u$ holopoema es un poema concebido, hecho $y$ presentado holográficamente. Esto significa, primero que nada, que dicho poema es organizado de manera no lineal en un espacio inmaterial tridimensional y que, inclusive mientras el lector o espectador lo observa, cambia y da lugar a nuevos significados. De este modo, mientras el espectador lee el poema en el espacio - esto es, se mueve alrededor del hologramamodificará constantemente la estructura del texto. El holopoema es un evento espacio temporal: evoca procesos mentales y no su resultado (Kac, 1997: web).
}

La lírica convertida en holograma es diseñada en atención al punto de vista espacio-temporal del receptor, a su relación dinámica e instantánea con el texto y al propio proceso receptivo como acto comunicativo único y necesario para la comprensión de la obra. En consecuencia de esta concepción poética, la holopoesía no podría ser publicada en un libro-poemario sin sufrir importantes transformaciones en su forma y en su fondo, puesto que su desarrollo está intrínsecamente relacionado con el medio para el que ha sido ideada y con el que mantiene un tratamiento inherente. Del mismo modo, un holopoema no se identifica solo por ser publicado en cinta holográfica, sino que, por el contrario, "lo que importa es la creación de nuevas sintaxis, movilidad, no linealidad, interactividad, fluidez, discontinuidad y 
comportamiento dinámico solo posible en el espacio tiempo holográfico" (Kac, 1997: web). La noción de holopoesía transciende el medio y alcanza la propia médula de su esencia poética, de su actitud artística, como afirma María Teresa Vilariño: "la holopoesía propone un original territorio dentro de la exploración poética, en el que se cuestionan, obligatoriamente, la ontología, la epistemología y la pragmática de la creación lírica" (2006: 112). E cuestionamiento multidisciplinar para la creación lírica, tanto desde una perspectiva teórica como desde una perspectiva pragmática, forma parte de la propia idiosincrasia del género, de su propia voluntad rupturista y revolucionaria.

Este arte verbal coincide con la "escritura nómade", según Belén Gache (2006), esto es, con un modo de expresión que rechaza los límites espaciales de la página:

La concepción del libro tal como lo conocemos hoy, con sus convenciones de formato y paratexto, corresponde a la modernidad. Este libro es portable, mercantilizable y coleccionable. Sus tapas lo cierran al mundo, lo separan como entidad aislada. En los textos digitales, por el contrario, es imposible hablar de una estricta separación entre los mismos. La capacidad de crear hipervínculos hace pensar incluso en la posibilidad de una biblioteca universal cuyos fragmentos estuvieran todos interconectados. El orden de los textos, por otra parte, estará determinado en cada caso por una particular lectura.

Los renglones impresos en las páginas de los libros semejan las rejas de una prisión que mantiene prisionero al texto. En la escritura digital, en cambio, las páginas se alternan y se horadarán, se expanden hacia otros textos y hacia otras dimensiones semánticas (2006: 151).

La poesía hologramática huye de la idea del texto estático, "prisionero" en el libro, convertido en una "entidad aislada". Asimismo, desafía la visualización total de la página, como reconoce Eduardo Kac: "a mí me interesaba deshacer lo que heredamos de las vanguardias clásicas, [...] la "sintaxis visual" que te ofrece una aprehensión total de la página simultáneamente" (2015: vídeo); a lo que añade: "me interesaba ir más allá de esta lógica del poema como un objeto gráfico totalizante, totalitario, a mi entender, y también ir más allá de las posibilidades y limitaciones de las explotaciones materiales de la poesía" (2015: vídeo). Estas creaciones de Kac se alejan de la "mirada totalitaria, totalizante" (2015: vídeo) y apuestan por el ángulo del receptor, por la importancia de su óptica, de su movimiento y de su aproximación a la obra. 
Esta singularidad supone la mayor diferencia con respecto a la poesía visual, dado que, como resume María José Vega:

Frente a la estabilidad y permanencia de la poesía del plano y de la página, la nueva holopoesía se asocia a la inestabilidad, a la inmaterialidad, al espacio, a la ilusión, al movimiento, a la transformación. La experiencia lectora no finaliza al cerrar al libro, sino al apagar la luz o al abandonar el museo (2002: 58).

La experiencia lectora se manifiesta, por ende, significativamente nueva, distinta, crucial para comprender y definir el significado del holopoema.

En la web del autor (http://www.ekac.org/allholopoems.html) se pueden contemplar algunas imágenes pertenecientes a sus hologramas, vistas y detalles que, a pesar de no ofrecer la interactividad que conlleva asistir a la exposición real de la obra, como se advierte en la página, ilustran algunos aspectos de los trabajos, como su potencial visual, su mutabilidad, la ausencia de linealidad o la sensación de perspectivismo y subjetividad que transmiten los propios holopoemas, que parecen ser autoconscientes de su propia condición holográfica.

Si tomamos como muestra las imágenes del holopoema "Maybe then, if only as", de 1993, captadas y publicadas en la web de Kac, podemos comprender el dinamismo del poema, la dificultad para comprender con nitidez un mensaje que se transmite voluntariamente cambiante, que se escurre en el espacio y con el que solo podemos interactuar a través de nuestra relación con el espacio que nos separa del poema.

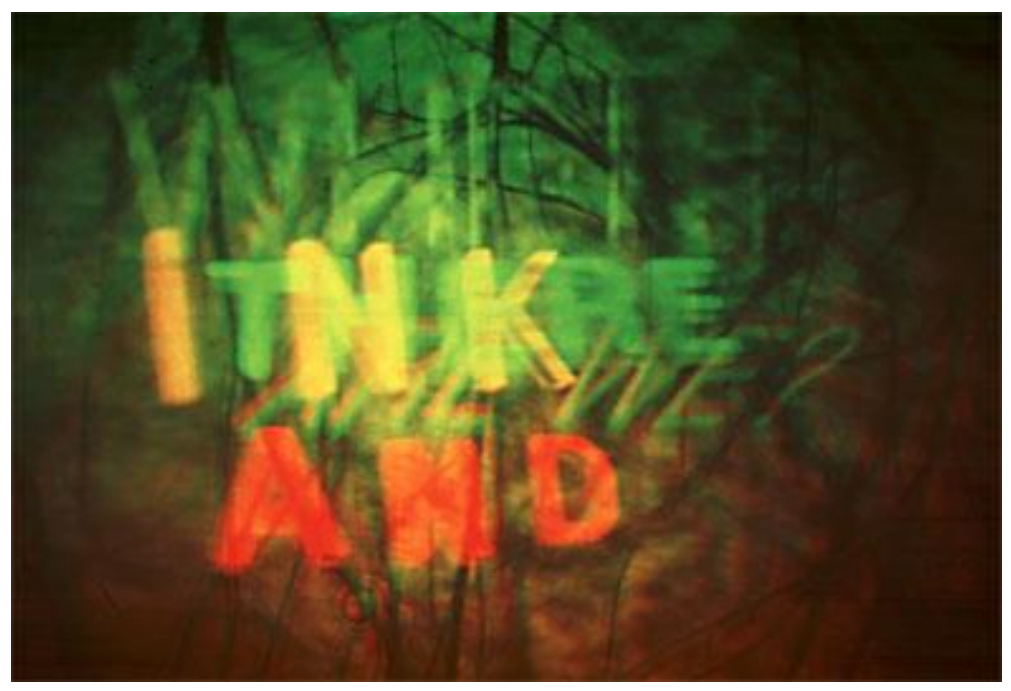

Fig. 1 Eduardo Kac, "Maybe then, if only as" http://www.ekac.org/allholopoems.html 


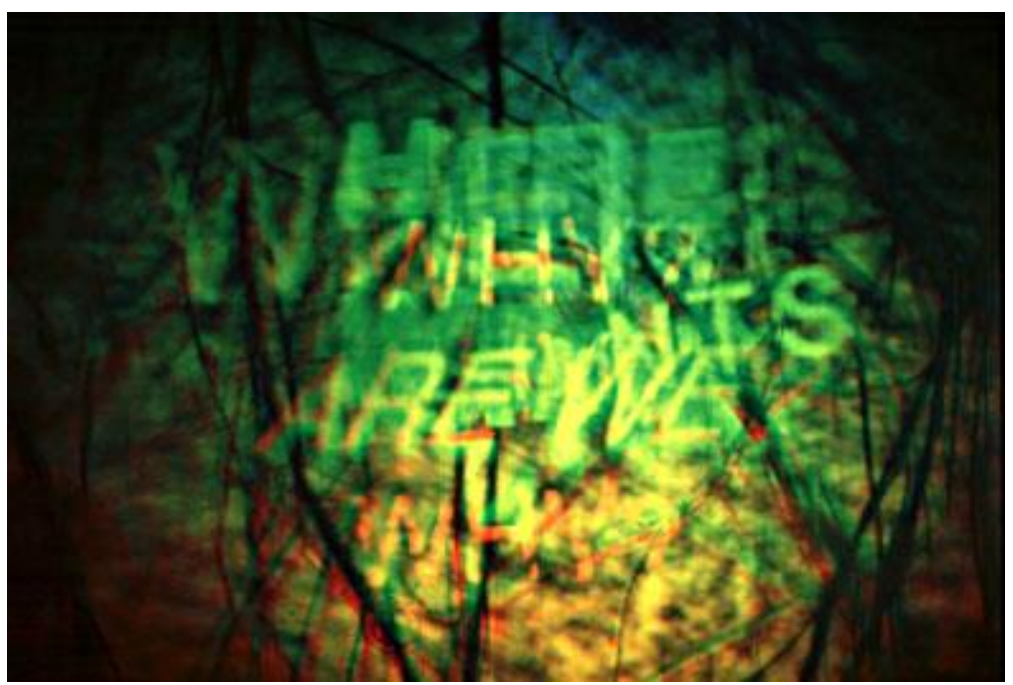

Fig. 2 Eduardo Kac, "Maybe then, if only as" http://www.ekac.org/allholopoems.html

La plasticidad adquiere una gran relevancia en este poema inesperado y sorprendente que genera incertidumbre constante, el "cómo" se funde con el "qué" en una evocación al principio modernista del "arte por el arte" y el mensaje pierde importancia con respecto a la experiencia, así como el significado con respecto al significante.

Dada la importancia del medio, uno de los problemas más significativos de este género artístico es el estado efímero de los dispositivos y el riesgo a que las piezas artísticas sean también efímeras. En el caso de la serie Holopoetry el autor, conocedor de esta contrariedad, ejecutó, gracias al trabajo de un equipo de profesionales, un traslado de sus holopoemas de Minitel (el servicio de videotex predecesor de la World Wide Web al que se accedía a través del teléfono y que se comercializó a principios de los años ochenta) a medios actuales. Solo la migración de los poemas holográficos a un nuevo ecosistema vivo y conectado asegura su supervivencia, pero, para fortuna de la holopoesía, la técnica posibilita el tránsito entre canales, el nomadismo del artefacto a un entorno donde pueda desarrollarse en similares circunstancias y con similares cualidades.

El encuentro ideal con el holopoema debe ser directo y personal, en una de las muchas colecciones del autor que han sido expuestas en Brasil, Estados 
Unidos y Europa, puesto que si el holopoema se percibe a través de un vídeo grabado por otro "lectoespectador" (Mora, 2012) no se vive "la experiencia real y verdadera de la obra" (Kac, 2015: vídeo), sino una reproducción de esta, el ejemplo narrado por una subjetividad distinta. Este requisito pone en evidencia la esencia personal, única e intransferible del proceso receptor, así como del aura benjaminiana de la obra, que no ha sido concebida para la reproductibilidad masiva, sino para ser admirada como un objeto de arte.

Por otro lado, el mencionado vínculo espacio-temporal con la obra y la voluntad de crear una "poesía perceptual" (Giovine, 2004: web), es decir, la abstracción de aquellas "manifestaciones poéticas que no tienen como soporte el papel y que surgieron a partir de los años ochenta del siglo pasado" (2004: web), permanece vigente en otros géneros explorados por el artista, como la "biopoesía" o "poesía biológica", realizada a través de un metabolismo vivo, o la "aromapoesía", pensada para ser leída a través de olfato. Dentro de sus experimentos de "bioarte" hay creaciones tan diversas y sorprendentes como las obras transgénicas "GFP Bunny", del año 2000, que consiste en un conejo verde fluorescente llamado "Alba" y creado a partir del ADN de medusas y conejos, y "Edunia", perteneciente a la obra titulada "Historia natural del enigma", una flor de ingeniería genética creada a partir de la petunia que contiene ADN del propio Kac y que fue desarrollada entre 2003 y 2008 y expuesta en 2009 y galardonada en este mismo año con el premio Golden Nica 2009. Estas controvertidas piezas cuestionan los límites de la exploración humana desde el punto de vista científico y también desde el punto de vista artístico y participan en el eterno diálogo entre ciencia y ética.

Otro elemento común es su carácter efímero y voluble, según su propia declaración: "yo busco crear una poesía que resista la tentativa no solamente de interpretación pero también [sic] del acto perceptual de lectura, que sea fluida, que cambie" (2015: vídeo). Fiel a este principio, la poesía de Eduardo Kac y, en concreto, la holopoesía de Eduardo Kac es para el lector una experiencia estética fugaz y espontánea, performática, pensada para ser observada, impalpable, incorpórea, evanescente. 


\section{Reflexiones finales}

La holopoesía de Eduardo Kac aúna ilusión y técnica y cede al lector la posibilidad de ser "el artífice que pone en funcionamiento el poema, con un componente de magia que armoniza con la propia magia de la lírica, con su cercanía y su intangibilidad" (Corral, 2015: 245). Si bien el receptor es imprescindible en cualquier acto comunicativo, en este acto comunicativo concreto se convierte en imprescindible desde el punto de vista de la interacción física: si el receptor no lee la obra desde su propia aproximación a ella y en dinamismo, la obra no tiene lugar, no sucede. No se trata, por tanto, de abrir el libro, no se trata de escuchar la música, de atender y/o contemplar; se trata de relacionarse físicamente con la obra, en una danza ineludible que activa el texto y le da sentido.

Con respecto a una posible evolución cualitativa de la holopoesía, resulta sugerente la idea de Kac de que "algún día los hologramas también podrán ser escribibles. Cuando eso ocurra, surgirán nuevas posibilidades y la holopoesía nos llevará a nuevas áreas de experimentación poética" (1997: web). Mientras la técnica permita avanzar es probable que el interés humano por conocer nuevos soportes y, sobre todo, nuevas alternativas creativas cumpla el propósito artístico. Por el momento, si bien Kac ha apostado por otros medios de expresión que siguen explorando los vínculos entre técnica y arte, en el género de la holopoesía no se ha producido una expansión generalizada ni han aparecido obras de gran relevancia y Kac sigue siendo el autor más estudiado en relación a la poesía hologramática, a pesar de su origen pionero, o quizá por él. Sí se han desarrollado, en cambio, géneros afines a la poesía holográfica que operan con la intangibilidad tridimensional, como la poesía cinética, en la que el poema se despliega en la pantalla a partir de los movimientos que realiza el lector, con trabajos como Enter:in 'Wodies', de 2001, con el diseño de Zuzana Husárová y la programación de L'ubomír Panák que funciona a través de los movimientos del lector, o la poesía en el marco de la realidad aumentada, que consiste en la proyección de una animación sobre un libro, que se visualiza atendiendo al cambio de página del

\footnotetext{
2 http://vimeo.com/29835469 [Fecha de consulta 31 de octubre de 2018]
} 
lector, como Between Page and Screen ${ }^{3}$, creado por la artista y poeta Amaranth Borsuk en colaboración con su marido Brad Bouse en 2012.

Una muestra afín y al mismo tiempo contrapuesta de la holopoesía de Kac podría ser la poesía para dispositivos móviles del canadiense Jason Edward Lewis, que ve la luz casi tres décadas después del primer holopoema de Eduardo Kac. En su proyecto P.o.E.M.M. (Poems for Excitable [Mobile] Media) ${ }^{4}$ para iPhone y iPad se muestran los trabajos realizados por Lewis desde 2010 hasta el momento y diseñados para ser leídos en tableta o iPhone a través de una interacción constante por parte del receptor con la obra, esta vez de forma táctil: mediante el acercamiento directo del dedo o los dedos que pulsan y manipulan las palabras que construyen cada poema y que requieren esa conexión para que se logre la culminación de la obra. Los artefactos de Lewis, al igual que los de Kac, destacan por su plasticidad visual, por su particularidad experimental y lúdica, así como por la interactividad continua con el receptor y por ser eventos espacio-temporales; sin embargo, la relación material física que ofrecen al espectador difiere de forma significativa. A pesar de esta importante diferencia, hay una clara analogía entre la concepción y el desarrollo de los poemas holográficos de Kac y las piezas de P.o.E.M.M. de Lewis, como si el espíritu de aquellos holopoemas hubiera germinado casi treinta años después en los poemas para dispositivos móviles del autor canadiense.

Por otro lado, la ilusión que genera la percepción de la obra en el receptor se podría entender como una metáfora de la ilusión que genera la percepción de los colores o de las palabras en el receptor (Corral, 2015: 246), de modo que quien interviene con el poema, lejos de asimilar su contenido de forma pasiva, atiende a su nacimiento y progreso espontáneo desde el asombro y el descubrimiento.

El contacto (sin tacto) del receptor con la hololírica de Kac rememora la actitud lúdica y cómplice de las vanguardias, su esteticismo, su deseo de

\footnotetext{
3 http://news.cnet.com/8301-17938_105-57373708-1/digital-pop-up-book-gets-poetic-with-qrcodes/ [Fecha de consulta 31 de octubre de 2018]

http://www.youtube.com/watch?v=1s-JFxEmtpY\&feature=youtu.beo [Fecha de consulta 22 de septiembre de 2018]

${ }^{4}$ http://www.poemm.net/ [Fecha de consulta 22 de septiembre de 2018]
} 
ruptura y sorpresa, así como la naturaleza etérea y abstracta de la poesía, simbólica, volátil y, en síntesis, intangible.

\section{Bibliografía}

AugÉ, Marc (2004). Los no lugares. Barcelona: Gedisa.

BAUDRILLARD, Jean (1993). Cultura y simulacro. Barcelona: Kairós.

BAUDRILLARD, Jean (2000). Pantalla total. Barcelona: Anagrama.

BAumAN, Zygmund (2003). La modernidad líquida. México D.F.: Fondo de Cultura Económica.

BoRsuk, Amaranth; Bouse, Brad (2012). Between Page and Screen. http://news.cnet.com/8301-17938_105-57373708-1/digital-pop-up-bookgets-poetic-with-qr-codes/ [Fecha de consulta: 31 de octubre de 2018].

CORRAL CAÑAS, Celia (2015). Nuevos ámbitos en la creación de arte verbal. Poesía española contemporánea en la red. Salamanca: Universidad de Salamanca, Tesis y disertaciones académicas (Tesis doctoral). Disponible en http://hdl.handle.net/10366/127372

Deleuze, Gilles; GuattaRI, Félix (2010). Rizoma. Introducción. Valencia: PreTextos, 2010.

FOUCAULT, Michael (1986). "Of other spaces." Diacritics, 16, pp. 22-27.

GACHE, Belén (2006). Escrituras nómades. Gijón: Trea.

GıIOVINE YÁÑEZ, María Andrea (2004). "Poesía perceptual: experiencias poéticas interactivas",

Revista laboratorio,

9. http://revistalaboratorio.udp.cl/num9_2014_art3_giovine/ [22 de septiembre de 2018].

HusÁRovÁ, Zuzana; PANÁK L'ubomír (2011). Enter:in 'Wodies. Vimeo http://vimeo.com/29835469 [Fecha de consulta: 31 de octubre de 2018].

HUIZINGA, Johan (1972). Homo ludens. Madrid: Alianza.

JoHnston, David (2011). Aesthetic Animism: Digital Poetry as Ontological Probe. Montreal: Concordia University, Tesis y disertaciones académicas (Tesis doctoral).

Disponible

en https://spectrum.library.concordia.ca/36284/

KAC, Eduardo (2015). "Confluencias artísticas en la holopoesía y la poesía digital”, Simposio Internacional Máquinas de Inminencia: Estéticas de la Literatura Electrónica, Centro Cultural Universitaria, 8 y 9 de octubre de 2015, Plataformas de la imaginación i escenarios de la literatura electrónica, México, Laboratorio de literaturas extendidas y otras materialidades, YouTube, 9 de diciembre de 2017. https://www.youtube.com/watch?v=aDg_4S-a3cc [Fecha de consulta: 22 de septiembre de 2018].

KAC, Eduardo (1997). "Holopoesía y más allá", Vórtice argentina. http://www.vorticeargentina.com.ar/poesiavisual/escritos/holopoesia_y_ mas_alla.html [Fecha de consulta: 22 de septiembre de 2018].

KAC, Eduardo. KAC. http://ekac.org/ [Fecha de consulta: 22 de septiembre de 2018].

LEWIS, Jason Edward. P.o.E.M.M. (Poems for Excitable [Mobile] Media). http://www.poemm.net [Fecha de consulta: 22 de septiembre de 2018]. 
LIPOVETSKY, Gilles (1990). El imperio de lo efímero. Barcelona: Anagrama.

MAFFESOLI, Michel (2001). El instante eterno. El retorno de lo trágico en las sociedades posmodernas. Buenos Aires: Paidós.

MCLUHAN, Marshall (1988). El medio es el mensaje. Barcelona: Paidós Studios. MolinUEVO, José Luis (2006). La vida en tiempo real. La crisis de las utopías digitales. Madrid: Biblioteca Nueva.

MORA, Vicente Luis (2012). El lectoespectador. Barcelona. Seix Barral.

VEGA, María José (2002). "Holopoemas. La palabra ilusoria", Quimera, número 220, pp. 55-58.

VILARIÑO PICOS, María Teresa (2006). "Redefiniendo la poesía experimental: la holopoesía de Eduado Kac". En Dolores Fernández López y Fernando Rodríguez-Gallego (coords.), Haciendo camino en la investigación literaria, Santiago de Compostela: Universidad de Santiago de Compostela, pp. 105-114.

Fecha de recepción: 27 de septiembre de 2018

Fecha de aceptación: 30 de noviembre de 2018 